\title{
Elaboração de caldo de peixe em cubos compactados utilizando pirambeba (Serrasalmus brandtii) e tilápia (Oreochromis niloticus)
}

\author{
Elaboration of fish bouillon cubes using pirambeba \\ (Serrasalmus brandtii) and tilapia (Oreochromis niloticus)
}

\author{
Luis Felipe Freitas Fabrício ${ }^{1 *}$; Maria Emília Sousa Gomes Pimenta²; \\ Tatiana Abreu Reis ${ }^{3}$; Taciene Carvalho Mesquita ${ }^{4}$; Katia Lumi Fukushima ${ }^{4}$; \\ Roseane Maria Evangelista Oliveira ${ }^{5}$; Márcio Gilberto Zangeronimo ${ }^{2}$
}

\section{Resumo}

\begin{abstract}
Caldos em cubos compactados são temperos muito apreciados por seu baixo custo e por conferir sabor a pratos geralmente à base de carboidratos. Objetivou-se elaborar caldos em cubos compactados, explorando as características nutricionais da pirambeba (Serrasalmus brandtii) e tilápia (Oreochromis niloticus), visando um novo produto para o mercado de temperos, além de contribuir para um correto destino de resíduos da indústria pesqueira. Foi elaborada uma formulação padrão onde $30 \%$ desta foi substituída pelas diferentes formas de processamento das espécies utilizadas, resultando em diferentes caldos de peixe, para os quais foram realizadas as análises de interesse. A composição centesimal dos temperos contendo espécies tilápia e pirambeba não apresentaram grandes diferenças, o que comprova que outros peixes ou resíduos da indústria pesqueira também podem contribuir para a fabricação de caldos. O caldo comercial apresentou menor variedade de ácidos graxos poli-insaturados, além de baixo teor dos minerais cálcio e fósforo e maior de extrato etéreo quando comparados com os caldos de peixe elaborados.

Palavras-chave: Resíduo de pescado, processamento, tempero, análise centesimal, oxidação lipídica
\end{abstract}

\begin{abstract}
Broth cubes are packed spices highly prized for their low cost and for the flavor given to dishes, usually carbohydrate-based. The objective of this work was to establish compressed broth cubes, exploiting the nutritional characteristics of pirambeba (Serrasalmus brandtii) and tilapia (Oreochromis niloticus), seeking a new product to the spice market, and contribute to a proper waste disposal of the fishing industry. A formulation of this pattern was prepared, where $30 \%$ was replaced by different forms of processing of the species used, resulting in different fish broth, to which analysis of interest were performed. From the analysis, it was concluded that the fish broth using ground tilapia presented the best characteristics when compared to commercial broth. Chemical composition of fish bouillon cubes with species and tilapia pirambeba showed no major differences, which proves that other waste of fish or the fishing industry may also contribute to the production of broths. The broth commercial was less variety of polyunsaturated fatty acids, and low contents of calcium and phosphorus minerals, and more lipids compared to fish broth prepared.
\end{abstract}

Key words: Fish waste, processing, seasoning, chemical composition, lipid oxidation

\footnotetext{
${ }^{1}$ Discente de Mestrado do Dept $^{\circ}$ de Ciências Veterinárias da Universidade Federal de Lavras, DMV/UFLA, Lavras, MG. E-mail: luis.felipe.zootecnista@hotmail.com

${ }^{2}$ Profs. do Dept ${ }^{\circ}$ de Ciências Veterinárias, DMV/UFLA, Lavras, MG. E-mail: maria.emilia@dca.ufla.br; zangeronimo@dmv.ufla.br

${ }^{3}$ Discente de Mestrado do Dept ${ }^{\circ}$ de Ciências dos Alimentos, DCA/UFLA, Lavras, MG. E-mail: tatianaabreureis@yahoo.com.br

${ }^{4}$ Graduanda(s) do Curso de Engenharia de Alimentos, Dept ${ }^{\circ}$ de Ciências dos Alimentos, DCA/UFLA, Lavras, MG. E-mail: tacienecarvalho@hotmail.com; fukushima_lumi@hotmail.com

${ }^{5}$ Discente de Doutorado do Dept ${ }^{\circ}$ de Ciências dos Alimentos, DCA/UFLA, Lavras, MG. E-mail: roseane-ufla@hotmail.com

* Autor para correspondência
} 


\section{Introdução}

Devido à falta de destino apropriado para resíduos da indústria pesqueira, novos produtos vêm sendo desenvolvidos para o consumo humano, uma vez que apresentam características relevantes para a área da nutrição e saúde. Considerando que a população vem se preocupando cada vez mais em consumir produtos saudáveis que ajudam a manter o equilíbrio nutricional. Como exemplo, os ácidos graxos de cadeia poliinsaturada das séries ômega 3 e 6 devem estar diariamente presentes nas dietas em quantidades adequadas (SIMOPOULOS, 1989). Desta forma, produtos a base de peixe merecem destaque na preferência do consumidor.

O processamento de pescado pela indústria alimentícia gera uma grande quantidade de resíduos que normalmente são descartados. Procedimentos tecnológicos para um melhor aproveitamento destes materiais são importantes para se evitar que os resíduos alimentares sejam subutilizados, e por consequência, desvalorizados (STORI, 2000; BENITES, 2003).

A elaboração de caldos de peixe em cubos compactados utilizando resíduos do processamento pescado visa explorar nutrientes e sabores em um novo produto para o mercado de temperos. Além de explorar estas características, pode-se presumir que uma produção em grande escala comercial reduziria o impacto ambiental provocado pelo descarte inadequado de resíduos (FERREIRA, 2002).

A pirambeba (Serrasalmus brandtii) não é cultivada comercialmente, porém, frequentemente está presente como fauna acompanhante em sistemas de produção, sendo considerada descarte. Por outro lado, a tilápia (Oreochromis niloticus) é um dos peixes de água doce com maior interesse comercial no mundo, gerando grande quantidade de resíduos quando fora do peso ideal de abate e após processamento. Desta forma, objetivou-se elaborar caldos de peixe de interesse nutricional, gastronômico e ecológico, utilizando duas espécies de peixes, a pirambeba e a tilápia.

\section{Material e Métodos}

\section{Obtenção das matérias primas}

O projeto foi realizado no Município de Lavras - MG, no Laboratório Central de Análises e no Laboratório de Carnes e Pescado do Departamento de Ciência dos Alimentos da Universidade Federal de Lavras (UFLA).

As matérias primas utilizadas, foram compostas principalmente de tilápia (a qual, no momento da despesca, se encontrava abaixo do peso de abate) e pirambeba, um peixe normalmente descartado por pescadores devido a sua grande quantidade de espinhas.

O processamento da matéria prima resultou em dois tipos de produtos: peixes moídos inteiros (PMI) em moedor elétrico de carne modelo C.A.F. 10I e carne mecanicamente separada (CMS) obtida através da despolpadora elétrica High Tech modelo HT 100C.

O delineamento experimental utilizado para comparação das diferentes matérias-primas foi um DIC (delineamento inteiramente casualizado), num fatorial $2 \times 2$ (2 espécies de peixe - tilápia e pirambeba - 2 tipos de processamento da matéria prima - PMI e CMS). Após este processamento prévio, foram realizadas as análises para obtenção da composição centesimal (umidade, proteína bruta, extrato etéreo e matéria mineral), de acordo com a AOAC (1990).

\section{Fabricação dos caldos em cubos compactados}

Para fabricação dos caldos em cubos compactados, foi utilizada a formulação apresentada na tabela 1 . 
Tabela 1. Formulação dos caldos de peixe em cubos compactados.

\begin{tabular}{lc}
\hline Ingrediente & Quantidade (\%) \\
\hline Peixe Processado - PMI e CMS & 30 \\
Sal & 50 \\
Gordura Vegetal & 2,5 \\
Amido de Milho & 4,5 \\
Açúcar & 1 \\
Alho & 4,5 \\
Salsa & 2,5 \\
Pimenta Malagueta & 1 \\
Louro & 0,5 \\
Glutamato Monossódico & 2 \\
Urucum & 1 \\
Ácido Cítrico & 0,5 \\
\hline
\end{tabular}

Fonte: Elaboração dos autores.

Todos os ingredientes, exceto o sal, foram moídos, pesados e homogeneizados em banho maria, à temperatura de $100{ }^{\circ} \mathrm{C}$ por 5 minutos. Em seguida, o sal foi adicionado à mistura formando uma massa a qual foi pesada em quantidades de aproximadamente $12 \mathrm{~g}$ e compactada em forma retangular adaptada para fabricação dos cubos.

Os cubos foram então colocados em estufa 65 ${ }^{\circ} \mathrm{C}$ por 12 horas, para eliminar o excesso de água. Em seguida foram submetidas às seguintes análises químicas e físico-químicas.

\section{Composição centesimal}

As análises para obtenção da composição centesimal (umidade, proteína bruta, extrato etéreo e matéria mineral) dos caldos de peixe fabricados e do caldo comercial, foram realizadas de acordo com a AOAC (1990).

\section{Minerais: cálcio e fósforo}

As leituras de minerais (cálcio e fósforo) foram realizadas em fotômetro de chama a partir dos extratos das amostras obtidas por digestão nítricoperclórica (DNP) e determinados segundo Malavolta, Vitti e Oliveira (1989).
Para a digestão nítricoperclórica foram pesados $0,5 \mathrm{~g}$ do caldo de peixe em tubo de digestão e adicionados $6 \mathrm{~mL}$ da mistura de ácido nítrico e ácido perclórico na proporção 2:1 (v/v). Os tubos foram levados para bloco digestor que teve sua temperatura aumentada gradativamente a $160{ }^{\circ} \mathrm{C}$, até reduzirem seu volume pela metade e então a temperatura foi aumentada para $210^{\circ} \mathrm{C}$ até o extrato apresentar-se incolor. Após esfriarem, foram adicionados aproximadamente $15 \mathrm{~mL}$ de água destilada e pesado o volume final para ser realizada a leitura em fotômetro de chama.

\section{Oxidação lipídica}

As análises de oxidação lipídica dos caldos foram realizadas utilizando-se a determinação de TBARS (substâncias reativas ao ácido tiobarbitúrico), conforme metodologia descrita por Tarladgis, Watts e Younathan (1960) com algumas modificações.

Foram pesados aproximadamente $10 \mathrm{~g}$ do caldo de peixe e adicionados $40 \mathrm{~mL}$ de ácido tricloroacético (TCA) a $5 \%$ e $1 \mathrm{~mL}$ de antioxidante BHT a $0,15 \%$. Após ser homogeneizada em Bag Mixer, a mistura foi filtrada em filtro de papel e logo após, o filtrado foi completado em balão volumétrico para o volume de $50 \mathrm{~mL}$ com TCA 5\%. Dois mililitros do filtrado foram pipetados em tubo de ensaio, adicionados 
dois mililitros de ácido tiobarbitúrico a $0,08 \mathrm{M} \mathrm{e}$ mantido por 5 minutos em banho maria de água fervente. Logo após foram realizadas as leituras em $531 \mathrm{~nm}$ onde os valores obtidos foram expressos em miligramas de malonaldeído por quilo de amostra através do cálculo:

mg de Malonaldeído/ $\mathrm{kg}$ de amostra = Valor da absorbância x 7,38

\section{Perfil de ácidos graxos}

O perfil de ácidos graxos foi obtido a partir dos ésteres resultantes da esterificação das amostras de cada tratamento, sendo submetidos à análise de cromatografia gasosa, em aparelho Shimadzu GC 2010.

Os ácidos graxos foram esterificados com uso de $4 \mathrm{~mL}$ de uma solução de $\mathrm{NaOH}$ 0,5 M em metanol, levando-se na sequencia a amostra ao banho fervente por 5 minutos. Após esse período as amostras foram resfriadas em água gelada. Em seguida, foi adicionado $5 \mathrm{~mL}$ do reagente esterificante (à base de ácido sulfúrico) às amostras, levando-as por mais 5 minutos ao banho fervente e novamente resfriando-se em água gelada. Após resfriamento, foram adicionados $4 \mathrm{~mL}$ de $\mathrm{NaCl}$ saturado e $5 \mathrm{~mL}$ de hexano. O sistema resultante de todas as etapas anteriormente mencionadas permaneceu em repouso por 10 minutos. A parte sobrenadante foi recolhida para frasco âmbar. O hexano foi evaporado com nitrogênio gasoso, em banho-maria a $55^{\circ} \mathrm{C}$.

Os ésteres resultantes da etapa de esterificação foram submetidos à análise de cromatografia gasosa, em aparelho Shimadzu GC 2010, com detector de ionização em chama (FID), utilizando-se coluna capilar $(100 \mathrm{~mm} \times 0,25 \mathrm{~mm} \times 0,2 \mu \mathrm{L})$. Foram utilizadas as seguintes condições cromatográficas, baseadas em testes realizados no referido aparelho:

Injetor: trabalhou no modo "split", utilizando o hélio como gás de arraste, num fluxo de 1,09 $\mathrm{mL} \cdot \mathrm{min}^{-1}$. Foi injetado $1 \mu \mathrm{L}$ de amostra, sendo o tempo de corrida de 60 minutos.
Coluna: temperatura inicial de $140{ }^{\circ} \mathrm{C}$, mantendo-se nessa temperatura por 5 minutos, elevando-se em uma taxa de $4^{\circ} \mathrm{C}$. $\min ^{-1}$ até $240^{\circ} \mathrm{C}$. A fase estacionária da coluna foi composta por biscianopropil polisiloxano.

A identificação e a quantificação dos ácidos graxos foram feitas por comparação dos tempos de retenção dos ésteres contidos no padrão Supelco ${ }^{\mathrm{TM}}$ 37 FAME MIX com os da amostra.

Delineamento estatístico para comparação dos diferentes caldos de peixe fabricados com um caldo comercial à base de pescado

Para comparação dos diferentes caldos elaborados foi utilizado um delineamento inteiramente casualizado, num fatorial $2 \times 2$ (2 espécies de peixe, 2 tipos de processamento da matéria prima). Um caldo comercial à base de pescado foi incluído, para uma comparação simples de média.

Os dados foram analisados por meio do pacote computacional SAS (SAS INSTITUTE, 1996), usando o teste T de Student e o teste Scott - Knott.

\section{Resultados e Discussão}

Composição centesimal e análises de cálcio e fósforo das matérias primas obtidas e dos caldos elaborados

O efeito isolado de espécie sobre as análises centesimais das matérias-primas obtidas foi significativo para todas as análises realizadas (Tabela 2). A matéria-prima tilápia apresentou valores superiores para umidade e matéria mineral quando comparados com os valores das mesmas análises para pirambeba. De acordo com Ogawa (1999), o músculo do pescado contém de 60 a $85 \%$ de umidade, sendo assim, os valores médios observados neste trabalho situam-se dentro dessa faixa. Já os valores de matéria seca, extrato etéreo e proteína bruta para tilápia foram inferiores $(\mathrm{P}<0,01)$ quando comparados com os valores de 
pirambeba. Segundo Pompeu (1999) a alimentação da pirambeba (Serrasalmus brandtii), em todas as classes de tamanho, é predominantemente carnívora e coincide com a dieta observada por Bedê, Santos e Alves (1993), enquanto Fitzsimmons (2000) afirma que a tilápia é de baixo nível trófico (onívora). Sendo assim este e outros vários fatores como a diferença entre as espécies, explicam o fato do teor de proteína bruta da pirambeba ser estatisticamente maior do que da tilápia. De acordo com Martins et al. (2009) a média de proteína bruta da carcaça de tilápias de diferentes idades e pesos varia em torno de 9 a 11\% enquanto Sampaio, Kubitza e Cyrino (2000) ao realizar trabalhos com espécies carnívoras, observou valores entre 8 a aproximadamente 14\% de proteína bruta na carcaça desses peixes.

Tabela 2. Valores médios, em porcentagem de matéria integral, das análises das matérias primas e nos caldos elaborados sobre o efeito isolado de espécies e dos tipos de processamento.

\begin{tabular}{|c|c|c|c|c|c|c|}
\hline \multicolumn{7}{|c|}{ Matéria Prima } \\
\hline & \multicolumn{2}{|c|}{ Espécie } & \multicolumn{2}{|c|}{ Processamento } & \multirow[b]{2}{*}{$\mathrm{CV}(\%)$} & \multirow[b]{2}{*}{ Erro Padrão } \\
\hline & Tilápia & Pirambeba & Moído & Despolpado & & \\
\hline Umidade* & $74,32 b$ & $71,85 a$ & $70,64 a$ & $75.52 b$ & 0,52 & 0,15 \\
\hline Matéria Seca* & $25,67 \mathrm{a}$ & $28,14 \mathrm{~b}$ & $29,35 b$ & $24,47 \mathrm{a}$ & 1,43 & 0,15 \\
\hline Proteína Bruta* & $11,18 \mathrm{a}$ & $13,67 b$ & $13,73 b$ & $11,12 \mathrm{a}$ & 5,85 & 0,29 \\
\hline \multicolumn{7}{|c|}{ Caldos Elaborados } \\
\hline & \multicolumn{2}{|c|}{ Espécie } & \multicolumn{2}{|c|}{ Processamento } & & \\
\hline & Tilápia & Pirambeba & Moído & Despolpado & $\mathrm{CV}(\%)$ & Erro Padrão \\
\hline Extrato Etéreo* & $3,90 \mathrm{a}$ & $5,01 \mathrm{~b}$ & $4,27 \mathrm{a}$ & $4,65 b$ & 2,52 & 0,14 \\
\hline Proteína Bruta* & $6,07 \mathrm{a}$ & $7,81 \mathrm{~b}$ & $7,34 \mathrm{a}$ & $7,16 \mathrm{a}$ & 6,34 & 0,18 \\
\hline Cálcio* & - & - & $0,58 b$ & $0,19 \mathrm{a}$ & 18,97 & 0,02 \\
\hline Fósforo* & - & - & $0,32 b$ & $0,15 \mathrm{a}$ & 19,5 & 0,01 \\
\hline
\end{tabular}

Média de 7 repetições.

*Médias seguidas de mesmas letras minúsculas na linha não diferem entre si pelo teste de t de Student $(\mathrm{P}>0,01)$.

Fonte: Elaboração dos autores.

O efeito isolado do tipo de processamento sobre a análise centesimal (Tabela 2) foi estatisticamente superior para o processamento moído nas análises de matéria seca, matéria mineral e proteína bruta quando comparados com o processamento despolpado. Por outro lado os valores de umidade e extrato etéreo foram estatisticamente menores $(\mathrm{P}<0,01)$ quando comparados aos valores do processamento despolpado.

As interações entre as espécies e os tipos de processamento das matérias-primas foram significativas apenas para as análises de matéria mineral e extrato etéreo (Tabela 3). 
Tabela 3. Valores médios, em porcentagem de matéria integral, das análises das matérias primas e nos caldos elaborados da interação entre espécies e tipos de processamento.

\begin{tabular}{|c|c|c|c|c|c|}
\hline \multicolumn{6}{|c|}{ Matéria Prima } \\
\hline & & Tilápia*1 & Pirambeba*1 & $\mathrm{CV}(\%)$ & Erro Padrão \\
\hline \multirow{2}{*}{ Matéria Mineral } & Moído** & $4,77 \mathrm{bB}$ & $3,91 \mathrm{aB}$ & 1,96 & 0,03 \\
\hline & Despolpado** & $1,66 \mathrm{aA}$ & $2,16 \mathrm{bA}$ & 1,96 & 0,03 \\
\hline \multirow{2}{*}{ Extrato Etéreo } & Moído² & $3,46 \mathrm{aA}$ & $5,64 \mathrm{bA}$ & 10,02 & 0,3 \\
\hline & Despolpado $^{2}$ & $5,84 \mathrm{aB}$ & $6,18 \mathrm{aA}$ & 10,02 & 0,3 \\
\hline \multicolumn{6}{|c|}{ Caldos elaborados } \\
\hline & & Tilápia* & Pirambeba* & $\mathrm{CV}(\%)$ & Erro Padrão \\
\hline \multirow{2}{*}{ Umidade } & Moído** & $16,71 \mathrm{bA}$ & $11,03 \mathrm{aA}$ & 1,67 & 0,15 \\
\hline & Despolpado** & $17,95 \mathrm{bB}$ & $16,94 \mathrm{aB}$ & 1,67 & 0,15 \\
\hline \multirow{2}{*}{ Matéria Seca } & Moído** & $83,28 \mathrm{aB}$ & $88,97 \mathrm{bB}$ & 0,31 & 0,15 \\
\hline & Despolpado** & $82,04 \mathrm{aA}$ & $83,05 \mathrm{bA}$ & 0,31 & 0,15 \\
\hline \multirow{2}{*}{ Matéria Mineral } & Moído** & $60,20 \mathrm{aB}$ & $60,03 \mathrm{aB}$ & 0,86 & 0,28 \\
\hline & Despolpado** & $55.63 \mathrm{aA}$ & $58,05 \mathrm{bA}$ & 0,86 & 0,28 \\
\hline \multirow{2}{*}{ Cálcio } & Moído** & $0,66 \mathrm{bB}$ & $0,49 \mathrm{aB}$ & 18,97 & 0,04 \\
\hline & Despolpado** & $0,16 \mathrm{aA}$ & $0,21 \mathrm{aA}$ & 18,97 & 0,04 \\
\hline
\end{tabular}

Média de 7 repetições.

**Médias seguidas de mesmas letras minúsculas na linha não diferem entre si pelo teste de $\mathrm{t}$ de Student $(\mathrm{P}>0,01)$.

*Médias seguidas de mesmas letras maiúsculas na coluna não diferem entre si pelo teste de $\mathrm{t}$ de Student $(\mathrm{P}>0,01)$.

${ }^{2}$ Médias seguidas de mesmas letras minúsculas na linha não diferem entre si pelo teste de $t$ de Student $(\mathrm{P}>0,05)$.

${ }^{1}$ Médias seguidas de mesmas letras maiúsculas na coluna não diferem entre si pelo teste de $t$ de Student $(\mathrm{P}>0,05)$.

Fonte: Elaboração dos autores.

A tilápia e a pirambeba quando moídas apresentaram médias, em porcentagem, maiores de matéria mineral do que quando despolpadas $(\mathrm{P}<0,01)$. Os procedimentos empregados para obtenção das duas diferentes matérias-primas explica esse fato, uma vez que para moagem dos peixes os mesmos foram eviscerados e posteriormente moídos inteiros. Logo ossos e espinhas ricos em minerais constituíram a matéria-prima moída. Segundo Souza et al. (2004) os valores médios de matéria mineral para tilápia inteira é de $3,41 \%$, enquanto o filé com a ausência de espinhas é em média 1,04\%.

Quando foi analisada apenas a matéria-prima moída, constatou-se que aquela originária das tilápias apresentou maior quantidade de minerais que a proveniente de piranhas $(\mathrm{P}<0,01)$.

Em contrapartida, para a matéria-prima despolpada observou-se que a pirambeba apresentou maiores porcentagens de matéria mineral $(\mathrm{P}<0,01)$ que a tilápia, provavelmente devido a diferenças normais entre espécies. Como os valores observados foram superiores ao limite mínimo comumente encontrado, considera-se que os mesmos apresentam-se normais.

Não foram observadas diferenças estatísticas $(\mathrm{P}<0,05)$ para a análise de extrato etéreo das espécies tilápia e pirambeba quando despolpadas, por outro lado, tilápia apresentou valor inferior $(\mathrm{P}<0,05)$ em relação à pirambeba quando utilizado o processamento moído. Ao se observar o processamento moído e o despolpado da pirambeba, não foram observadas diferenças $(\mathrm{P}<0,05)$. Já para tilápia, o processamento moído mostrou ser estatisticamente inferior $(\mathrm{P}<0,05)$ ao processamento despolpado na porcentagem média de extrato etéreo. Parte dos valores obtidos nas diferentes análises de composição centesimal para as matérias-primas, estão de acordo com Beirão et al. (2000), que diz que a composição química de peixes, crustáceos e moluscos, varia entre 70 a $85 \%$ de umidade, 20 a $25 \%$ de proteína, 1 a $1,55 \%$ de cinzas e 1 a $10 \%$ de 
gordura. Segundo o mesmo autor, essa composição é variável, dependendo da espécie, estado nutricional, sazonalidade, idade, parte do corpo e condições gonadais as quais explicam as diferenças encontradas no presente trabalho.

Ao observar o efeito isolado de espécie sobre a composição centesimal dos caldos elaborados, o caldo elaborado com tilápia revelou valores estatisticamente inferiores $(\mathrm{P}<0,01)$ quando comparada a pirambeba, para todas as análises, exceto para umidade (Tabela 2).

Os caldos elaborados com matéria-prima de processamento moído apresentaram valores menores para umidade e extrato etéreo $(\mathrm{P}<0,01)$ quando comparado aos caldos elaborados com matéria-prima de processamento despolpado. Já os valores de matéria mineral foram maiores $(\mathrm{P}<0,01)$ para os caldos elaborados com matéria prima de processamento moído quando comparados com os elaborados com matéria prima de processamento despolpado, uma vez que no processamento moído da matéria prima, toda a estrutura óssea é incorporada ao produto final. Não houve diferença $(\mathrm{P}>0,05)$ para o teor de proteína bruta dos caldos quando observado o efeito isolado de processamento da matéria-prima utilizada para a fabricação dos mesmos.

Houve interação entre espécies e tipos de processamento sobre os caldos elaborados $(\mathrm{P}<0,01)$ para as análises de umidade, matéria seca e matéria mineral (Tabela 3).

A interação das espécies e dos tipos de processamento apresentaram efeito sobre as médias de umidade quando comparados os caldos elaborados, uma vez que estes quando elaborados com tilápia, em ambos os processamentos, foram superiores estatisticamente $(\mathrm{P}<0,01)$ aos caldos elaborados com pirambeba em ambos os tipos de processamento, moída e despolpada. Por outro lado os caldos elaborados com tilápia e pirambeba moídas foram inferiores $(\mathrm{P}<0,01)$ aos caldos elaborados com tilápia e com pirambeba quando despolpadas.
Consequentemente, o mesmo se observou para a análise de matéria seca, porém de maneira inversa.

Ao se observar a interação entre as diferentes espécies e os tipos de processamento para a análise de matéria mineral dos caldos, observouse que os mesmos quando elaborados com tilápia ou pirambeba com processamento moído, foram estatisticamente iguais $(\mathrm{P}>0,01)$. Já os caldos elaborados com tilápia foram estatisticamente inferiores $(\mathrm{P}<0,01)$ aos caldos elaborados com pirambeba ambos sob processamento despolpado.

Os caldos elaborados com tilápia e pirambeba moídas apresentaram médias de matéria mineral estatisticamente superiores $(\mathrm{P}<0,01)$ aos caldos elaborados com tilápia e pirambeba quando despolpadas.

Para os caldos elaborados, o efeito isolado das espécies não apresentou diferenças para ambos os minerais $(\mathrm{P}>0,05)$. Por outro lado, o efeito isolado dos tipos de processamento apresentou diferenças $(\mathrm{P}<0,01)$ como se pode observar na Tabela 2 .

Os caldos elaborados com matéria-prima moída apresentaram maiores porcentagens de cálcio e fósforo $(\mathrm{P}<0,01)$, uma vez que a matéria prima deste processamento foi constituída pelo peixe inteiro, eviscerado e sem escamas.

Para cálcio houve a interação $(\mathrm{P}<0,05)$ entre as espécies e os tipos de processamento (Tabela 3 ).

Para a análise de cálcio, os caldos elaborados com tilápia e pirambeba quando despolpadas, não diferiram $(\mathrm{P}>0,05)$. Já para o caldo elaborado com tilápia moída, observou-se uma superioridade $(\mathrm{P}<0,05)$ na média de cálcio deste em relação ao caldo elaborado com pirambeba moída. Tanto o caldo elaborado com tilápia moída quanto o caldo elaborado com pirambeba moída, apresentaram valores superiores $(\mathrm{P}<0,05)$ de cálcio aos caldos elaborados com tilápia e pirambeba quando despolpadas. 
Comparação da composição centesimal e das análises de cálcio e fósforo dos caldos elaborados com um caldo comercial elaborado a partir de pescado

Grandes diferenças na análise centesimal foram observadas entre os caldos elaborados e o caldo comercial. Estes valores estão demonstrados na Tabela 4.

O caldo elaborado com tilápia despolpada apresentou o maior e o menor valor $(\mathrm{P}<0,01)$ para umidade e matéria seca, respectivamente, seguido dos caldos elaborados com tilápia moída e pirambeba despolpada que não diferiram entre si $(\mathrm{P}>0,01)$, mas tiveram valores superiores ao caldo elaborado com pirambeba moída. O caldo comercial apresentou um valor consideravelmente menor de umidade e, consequentemente, muito maior de matéria seca quando comparado aos caldos elaborados. A matéria mineral do caldo elaborado com tilápia despolpada foi menor $(\mathrm{P}<0,01)$ do que o caldo elaborado com pirambeba despolpada e o caldo comercial, os quais não diferiram entre si $(\mathrm{P}>0,01)$. Entretanto, os maiores valores foram dos caldos elaborados com tilápia moída e pirambeba moída, os quais foram estatisticamente iguais $(\mathrm{P}>0,05)$. Os menores valores de extrato etéreo foram dos caldos elaborados com tilápia moída e tilápia despolpada que foram iguais estatisticamente, assim como os caldos elaborados com pirambeba moída e pirambeba despolpada, iguais estatisticamente $(\mathrm{P}<0,01)$, mas que apresentaram valores intermediários entre os anteriores. Já o caldo comercial, apresentou o maior teor de extrato etéreo $(\mathrm{P}<0,01)$. Os valores de proteína bruta dos caldos elaborados com pirambeba moída e pirambeba despolpada foram semelhantes $(\mathrm{P}>0,05)$, porém superiores $(\mathrm{P}<0,05)$ aos caldos elaborados com tilápia moída, tilápia despolpada e o caldo comercial, os quais não diferiram entre si $(\mathrm{P}>0,05)$. De acordo com os dados obtidos por Guimarães e Marquez (2002) os caldos encontrados no mercado apresentam aproximadamente 2,9 a $4,3 \%$ de umidade, 16,6 a $17,6 \%$ de extrato etéreo, 8,2 a $8,5 \%$ de proteína bruta e de 54,1 a $61,2 \%$ de matéria mineral. Sendo assim, os caldos de peixe elaborados foram semelhantes em proteína bruta e matéria mineral, porém apresentaram valores elevados de umidade e valores reduzidos de extrato etéreo quando comparados aos caldos disponíveis no mercado, uma vez que os caldos elaborados não apresentam grandes quantidades de gordura vegetal em sua formulação.

Tabela 4. Valores médios, em porcentagem de matéria integral, da composição centesimal e análises de cálcio e fósforo dos caldos elaborados e do caldo comercial.

\begin{tabular}{lccccccc}
\hline & $\begin{array}{c}\text { Tilápia } \\
\text { Moída }\end{array}$ & $\begin{array}{c}\text { Tilápia } \\
\text { Despolpada }\end{array}$ & $\begin{array}{c}\text { Pirambeba } \\
\text { Moída }\end{array}$ & $\begin{array}{c}\text { Pirambeba } \\
\text { Despolpada }\end{array}$ & $\begin{array}{c}\text { Caldo } \\
\text { Comercial }\end{array}$ & $\begin{array}{c}\text { CV } \\
(\%)\end{array}$ & $\begin{array}{c}\text { Erro } \\
\text { Padrão }\end{array}$ \\
\hline Umidade* $_{\text {Matéria Seca* }}^{16,71 \mathrm{c}}$ & $17,95 \mathrm{~d}$ & $11,03 \mathrm{~b}$ & $16,94 \mathrm{c}$ & $1,81 \mathrm{a}$ & 1,61 & 0,12 \\
Matéria Mineral* $^{*}$ & $83,28 \mathrm{~b}$ & $82,04 \mathrm{a}$ & $88,97 \mathrm{c}$ & $83,05 \mathrm{~b}$ & $98,18 \mathrm{~d}$ & 0,24 & 0,12 \\
Extrato Etéreo* $^{*}$ & $03,69 \mathrm{a}$ & $55,63 \mathrm{a}$ & $60,03 \mathrm{c}$ & $58,05 \mathrm{~b}$ & $57,55 \mathrm{~b}$ & 0,74 & 0,25 \\
Proteína Bruta** $^{*}$ & $06,73 \mathrm{a}$ & $06,66 \mathrm{a}$ & $04,85 \mathrm{~b}$ & $05,18 \mathrm{~b}$ & $19,74 \mathrm{c}$ & 6,33 & 0,27 \\
Cálcio* & $0,66 \mathrm{c}$ & $0,16 \mathrm{a}$ & $0,96 \mathrm{~b}$ & $07,67 \mathrm{~b}$ & $06,27 \mathrm{a}$ & 7,55 & 0,31 \\
Fósforo* & $0,37 \mathrm{~d}$ & $0,13 \mathrm{~b}$ & $0,28 \mathrm{c}$ & $0,21 \mathrm{a}$ & $0,12 \mathrm{a}$ & 19,73 & 0,03 \\
\hline
\end{tabular}

Média de 7 repetições.

*Médias seguidas de mesmas letras minúsculas na linha não diferem entre si pelo teste $\mathrm{Scott}-\mathrm{Knott}(\mathrm{P}>0,01)$.

**Médias seguidas de mesmas letras minúsculas na linha não diferem entre si pelo teste Scott - Knott $(\mathrm{P}>0,05)$.

Fonte: Elaboração dos autores. 
A comparação entre os caldos de peixe elaborados e o caldo comercial quanto à porcentagem de cálcio e fósforo presentes nos mesmos, encontra-se na tabela 4 .

A partir da análise de cálcio, pode-se observar que o caldo comercial foi estatisticamente semelhante $(\mathrm{P}>0,05)$ aos caldos elaborados com tilápia despolpada e pirambeba despolpada. Porém, estes apresentaram valores estatisticamente inferiores $(\mathrm{P}<0,01)$ ao caldo elaborado com pirambeba moída e tilápia moída sendo que o ultimo apresentou o maior valor.

Não houve diferença entre os caldos elaborados com tilápia despolpada e pirambeba despolpada $(\mathrm{P}<0,01)$ quando observadas as porcentagens de fósforo presentes nos mesmos, mas foram superiores $(\mathrm{P}<0,01)$ ao caldo comercial e inferiores $(\mathrm{P}<0,01)$ ao caldo elaborado com pirambeba moída. $\mathrm{O}$ caldo elaborado com tilápia moída apresentou o maior teor de fósforo $(\mathrm{P}<0,01)$.

\section{Oxidação lipídica dos caldos de peixe elaborados}

Segundo Angelo (1996), a análise de TBA quantifica o malonaldeído(MDA), um dos principais produtos de decomposição dos hidroperóxidos de ácidos graxos poliinsaturados, formado durante o processo oxidativo.

A interação entre os caldos elaborados e os dias observados foram altamente significativos. (Tabela 5).

Tabela 5. Valores médios observados de malonaldeídos, em miligramas por quilo de amostra, dos caldos elaborados em diferentes dias e a concentração máxima de malonaldeídos dos caldos de peixe elaborados com suas respectivas oxidações máximas, em dias, estimadas.

\begin{tabular}{lcccccc}
\hline & $\begin{array}{c}\text { Tilápia } \\
\text { Moída }\end{array}$ & $\begin{array}{l}\text { Tilápia } \\
\text { Despolpada }\end{array}$ & $\begin{array}{l}\text { Pirambeba } \\
\text { Moída }\end{array}$ & $\begin{array}{c}\text { Pirambeba } \\
\text { Despolpada }\end{array}$ & $\begin{array}{l}\text { CV } \\
(\%)\end{array}$ & $\begin{array}{l}\text { Erro } \\
\text { Padrão }\end{array}$ \\
\hline 0 Dia* & $1,10 \mathrm{a}$ & $1,21 \mathrm{~b}$ & $1,43 \mathrm{c}$ & $1,64 \mathrm{~d}$ & 3,77 & 0,03 \\
14 Dias* & $1,16 \mathrm{a}$ & $1,35 \mathrm{~b}$ & $1,53 \mathrm{c}$ & $1,76 \mathrm{~d}$ & 3,77 & 0,03 \\
28 Dias* & $1,57 \mathrm{a}$ & $1,94 \mathrm{c}$ & $1,80 \mathrm{~b}$ & $2,11 \mathrm{~d}$ & 3,77 & 0,03 \\
42 Dias* & $2,67 \mathrm{a}$ & $3,27 \mathrm{~b}$ & $3,51 \mathrm{c}$ & $4,24 \mathrm{~d}$ & 3,77 & 0,03 \\
Máximo de Malonaldeídos & 7,19 & 5,23 & 9,80 & 9,52 & - & - \\
(mg/kg) & 75 & 57 & 74 & & & \\
Dias para Oxidação Lipídica & 75 & & & & & - \\
Máxima & & & & & & \\
\hline
\end{tabular}

Média de 7 repetições.

*Médias seguidas de mesmas letras minúsculas na linha não diferem entre si pelo teste Scott - Knott $(\mathrm{P}>0,01)$.

Fonte: Elaboração dos autores.

A concentração de malonaldeídos nos caldos compactados apresentou um aumento significativo $(\mathrm{P}<0,01)$ quando observado em diferentes dias após a fabricação. No tempo 0 observou-se que o caldo elaborado com tilápia moída apresentou o menor valor, seguido dos caldos elaborados com tilápia despolpada, pirambeba moída e pirambeba despolpada. O mesmo observou-se aos 14 dias e aos 42 dias. Aos 28 dias o caldo elaborado com tilápia moída também foi o que apresentou um menor valor, porém desta vez seguido dos caldos elaborados com pirambeba moída, tilápia despolpada e pirambeba despolpada. Segundo Al-Kahtani, Abu-Tarboush e Bajaber (1996) o pescado pode ser considerado bom para o consumo, quando apresentar valores abaixo de $3 \mathrm{mg}$ de malonaldeído/kg de amostra.

Uma pequena diminuição nos valores das médias estimadas da concentração de malonaldeídos não representa uma diminuição da oxidação lipídica, pois 
trata-se apenas de um ajuste do modelo estatístico utilizado e representa uma pequena estabilização da oxidação inicial ocorrida nos caldos de peixe elaborados.

Ao se fazer a derivada da equação da reta e igualar esta a zero, pode-se determinar o ponto crítico, ou seja, o ponto máximo em que a curva pode chegar, tendo assim uma estimativa da concentração máxima de malonaldeídos que os caldos podem apresentar. A partir da concentração máxima de malonaldeídos no produto, pode-se calcular o tempo de prateleira máximo em que o produto ainda estrá adequado ao consumo (Tabela 5).

Para as duas espécies quando utilizado o processamento moído para fabricação dos caldos, observou-se um maior tempo para oxidação lipídica total, o que comprova que o processamento moído quando comparado ao processamento despolpado, proporciona uma menor oxidação lipídica. Segundo Morrissey et al. (1998) logo após o abate e durante o processamento, como nas diferentes matériasprimas utilizadas para fabricação dos caldos, ocorre a destruição da integridade das membranas celulares pelo corte das carnes e também uma propagação das reações oxidativas.

Perfil de ácidos graxos dos caldos de peixe elaborados e caldo comercial

Quando comparados os tempos de retenção do padrão Supelco ${ }^{\mathrm{TM}} 37$ FAME MIX com os das amostras esterificadas dos caldos elaborados e do caldo comercial, observou-se a presença de vários ácidos graxos poliinsaturados, principalmente das séries $\omega-3, \omega-6$ e $\omega-9$ nos caldos elaborados além de outros ácidos graxos, enquanto no caldo comercial o principal ácido graxo observado foi o linoléico (C18:2 - $\omega-6)$, provavelmente em maior quantidade devido a uma alta concentração de gordura vegetal em sua formulação.

Apesar dos caldos elaborados apresentarem uma grande variedade de ácidos graxos insaturados e poliinsaturados, não se pode compará-los nutricionalmente com o caldo comercial, uma vez que o perfil lipídico das espécies tilápia e pirambeba, pode ser alterado e bastante variado devido ao hábito alimentar dessas espécies.

A realização da análise do perfil de ácidos graxos dos caldos elaborados neste trabalho não teve como objetivo quantificar ou qualificar os mesmos, mas sim dar suporte a explicação da oxidação lipídica ocorrida nestes.

Os caldos elaborados com pirambeba moída e pirambeba despolpada apresentaram uma maior oxidação lipídica. A explicação para este fato se dá principalmente por estes caldos apresentarem uma maior variedade de ácidos graxos poliinsaturados, resultando em uma maior oxidação lipídica.

\section{Conclusão}

As diferenças entre as espécies tilápia e pirambeba quando observada a composição centesimal, foram muito pequenas o que comprovou que outros peixes ou resíduos da indústria pesqueira também podem contribuir para a fabricação dos caldos, podendo tornar o produto ainda melhor.

O caldo comercial utilizado foi inferior aos caldos de peixe elaborados, uma vez que estes apresentaram maior variedade de ácidos graxos poliinsaturados e também quantidades relevantes dos minerais cálcio e fósforo e menor extrato etéreo independentemente da espécie ou processamento.

Observando todas as análises realizadas, podese dizer que o caldo elaborado com tilápia moída foi o que apresentou as melhores características nutricionais e de estabilidade.

\section{Agradecimentos}

Ao Conselho Nacional de Desenvolvimento Científico e Tecnológico (CNPq) pela bolsa de estudos e pelo financiamento do projeto. 


\section{Referências}

AL-KAHTANI, H. A.; ABU-TARBOUSH, H. M.; BAJABER, A. S. Chemical changes after irradiation and post-irradiation storage in tilapia and Spanish mackerel. J. Food. Sci., Saudi Arabia, v. 61, n. 4, p. 729-733, 1996.

ANGELO, A. J. Critical reviews. Food Sci. Nutrition, New Orleans, LA, v. 36, n. 6, p. 175-224, 1996.

ASSOCIATION OF OFFICIAL ANALYTICAL CHEMIST - AOAC. $15^{\text {st }}$ ed. Washington, DC: Association Of Official Analytical Chemists, 1990. p. 1018.

BEDÊ, L. C. G. B.; SANTOS; C. B. M.; ALVES, P. A. Alimentação de peixes do reservatório da Pampulha, Belo Horizonte, MG, com ênfase na malacofagia. Revista Ceres, Viçosa, v. 40, n. 231, p. 429-437, 1993.

BEIRÃO, L. H.; TEIXEIRA, E.; MEINERT, E. M.; SANTO, M. L. P. E. Processamento e industrialização de moluscos. In: SEMINÁRIO E WORKSHOP TECNOLOGIA PARA APROVEITAMENTO INTEGRAL DO PESCADO, 2000, Campinas. Anais... Campinas: ITAL/CTC, 2000. p. 38-84.

BENITES, C. I.. Farinha de silagem de resíduo de pescado: elaboração, complementação com farelo de arroz e avaliação biológica em diferentes espécies. 2003. Dissertação (Mestrado em Engenharia e Ciência dos Alimentos) - Fundação Universidade Federal do Rio Grande, Rio Grande, RS.

FERREIRA, J. A. Resíduos sólidos. In: SISINNO, C. L. S.; OLIVEIRA, R. M. (Org.). Perspectivas atuais. Rio de Janeiro: Editora Fiocruz, 2002. p. 21.

FITZSIMMONS, K. Tilapia: most important aquaculture species of the $21^{\text {st }}$ century. In: FROM THE FIFTH INTERNATIONAL SYMPOSIUM ON TILAPIA AQUACULTURE, 1., 2000, Rio de Janeiro. Proceedings... Rio de Janeiro: American Tilapia Association and DPA/MA, 2000. p. 3-8.

GUIMARÃES, C. P.; MARQUEZ, U. M. L. Composição química de tabletes de caldo de carne: nitrogênio protéico, não-protéico e fenilalanina. Ciência e Tecnologia de Alimentos, Campinas, v. 22, n. 3, p. 308-313, set-dez. 2002.

MALAVOLTA, E.; VITTI, G. C.; OLIVEIRA, S. A. Avaliação de estudo nutricional de plantas. Piracicaba: Posfatos, 1989. 201 p.
MARTINS, T. R.; SANTOS, V. B.; PERES, P. V.; SILVA, T. T. Variação da composição química corporal de tilápias (Oreochromis niloticus) com o crescimento. Colloquium Vitae, Presidente Prudente, v. 1, n. 2, p. 117-122, 2009.

MORRISSEY, P. A.; SHEEHY P. J. A.; GALVIN, K.; KERRY, P. J.; BUCKLEY, D. J. Lipid stability in meat and meat products. Meat Science, Amsterdam, v. 49, n. 1, p. 73-86, 1998.

OGAWA, M. Alterações da carne de pescado por processamento e estocagem. In: OGAWA, M.; MAIA, E. L. (Ed.). Manual de pesca - ciência e tecnologia do pescado. São Paulo: Varela, 1999. p. 221-249.

POMPEU, P. S. Dieta da pirambeba Serrasalmus brandtii reinhardt (teleostei, characidae) em quatro lagoas marginais do rio São Francisco, Brasil. Revista Brasileira de Zoologia, Belo Horizonte, v. 16, p. 19-26, 1999. Suplemento 2.

SAMPAIO, A. M. B. M.; KUBITZA, F.; CYRINO, J. E. P. Relação energia: proteína na nutrição do tucunaré. Scientia Agrícola, Piracicaba, v. 57, n. 2, p. 213-219, 2000.

SAS INSTITUTE. Users guide: statistics 1989-1996. Version 6.11. Cary, North Carolina. 1996.

SIMOPOULOS, A. P. Summary of the nato advanced research workshop on dietary -3 and -6 fatty acids: biological effects and nutritional essentiality. American Institute of Nutrition, Philadelphia, v. 119, n. 4, p. 521528, 1989.

SOUZA, M. L. R.; BACARRIN, A. E.; VIEGAS, E. M. M.; KRONKA, S. N. Defumação da tilápia do nilo (Oreochromis niloticus) inteira eviscerada e filé: aspectos referentes às características organolépticas, composição centesimal e perdas ocorridas no processamento. Revista Brasileira de Zootecnia, Viçosa, MG, v. 33, n. 1, p. $27-$ 36, 2004.

STORI, F. T. Avaliação dos resíduos da industrialização do pescado em Itajaí e Navegantes (SC), como subsídio à implementação de um sistema gerencial de bolsa de resíduos. 2000. Monografia (Trabalho de conclusão de Curso) - Universidade do Vale do Itajaí, Santa Catariana.

TARLADGIS, B. G.; WATTS, B. M.; YOUNATHAN, M. T. A. A destillation method for the quantitative determination of malonaldeyde in rancid foods. $J$. American Oil Chemists Society, Champaign v. 37, n. 1, p. 44-48, 1960. 
